\title{
Aspergillus flavus endaortitis following aortic valvotomy
}

\author{
A. D. MALCOLM ${ }^{1}$, A. BAKERSPIGEL, and A. A. ENRIQUEZ \\ Department of Medicine, University of Western Ontario, and the Departments of Clinical \\ Microbiology and Pathology, Victoria Hospital, London, Ontario, Canada
}

\begin{abstract}
Aspergillar endaortitis does not seem to have been described before in the English literature. Our patient had undergone aortic valvotomy and subsequently developed leg pains, migratory arthralgias, periarticular swelling, and general malaise. Mild intermittent pyrexia, evanescent petechiae, splinter haemorrhages, and peripheral small artery occlusion characterized the early course in hospital. Dramatic popliteal artery occlusion led to surgical recovery of embolic material packed with mycelia of Aspergillus flavus, but the patient died despite intravenous amphotericin B therapy. Necropsy revealed endaortitis and aspergilli were demonstrated in the wall of a saccular dilatation of the ascending aorta close to non-absorbable sutures.

The relevant literature is reviewed and attention is drawn to the current implications of knowledge relating to risk factors, diagnosis, and treatment. We suggest that cardiovascular aspergillosis will now be encountered more frequently and that a different therapeutic approach is justified.
\end{abstract}

Mycotic cardiovascular invasion, usually in the form of endocarditis, is now well recognized as a complication of open cardiac surgery (Andriole, Kravetz, Roberts, and Utz, 1962 ; Jamshidi, Pope, and Friedman, 1963 ; Newman and Cordell, 1964 ; Climie and Rachmaninoff, 1965; Lerner and Weinstein, 1966 ; McConnell and Roberts, 1967). Candida is the organism most commonly responsible but aspergillus endocarditis has been reported following Starr-Edwards mitral valve replacement (Newman and Cordell, 1964) and fascia lata aortic cusp advancement (Clinicopathological Conference, 1969 ; News and Notes, British Medical Journal, 1970). The much rarer, but nevertheless analogous, entity of aspergillus endaortitis appears to have been described but once and that by Hadorn (1960) following transaortic operation on a patient with subvalvular aortic stenosis.

\section{CASE REPORT}

A 34-year-old Caucasian travelling food salesman was admitted to Victoria Hospital, London, Ontario, in October 1969 because of pain in the calves and feet together with transient joint swelling and pain.

In March 1969 he had undergone aortic valvotomy under direct vision on cardiopulmonary bypass for relief of a stenosed congenitally bicuspid aortic valve.

1Address for reprints : Department of Medicine. The Middlesex Hospital, London WiN 8AA, England
At operation an angiographically demonstrable gross dilatation of the ascending aorta was confirmed and there was some calcification of the aortic valve cusps. His post-valvotomy cardiovascular status was excellent with a blood pressure of $115 / 85 \mathrm{mmHg}$ and no auscultatory evidence of aortic incompetence.

He remained well until four months before admission when an infection of carpentry cuts on the hands progressed to local cellulitis, which was successfully treated by oral penicillin for three days. One month later he had sudden right calf and right foot pain, with a cool, pale right foot. The pain lasted four days, and three more similar episodes followed in both legs. Two months before admission migratory severe arthralgias, periarticular swelling, and tenderness affected several joints including the ankles, knees, hips, and wrists. The symptoms lasted a few days and sometimes were sufficiently incapacitating to make walking difficult, though phenylbutazone was of some benefit. Thereafter nailfold splinter haemorrhages were seen and a few painful fingertip nodules healed without scarring. Slight anorexia supervened a week before he entered hospital.

Clinically the patient looked fit and was afebrile, with poor dentition and a few small, mobile, tender nodes palpable in the left axilla. The hands were unremarkable. The pulse was normal and regular and the blood pressure $120 / 90 \mathrm{mmHg}$. He had no ventricular hypertrophy or failure and auscultation revealed normal first and second heart sounds with a grade 2/6 aortic ejection systolic murmur which had not altered during his eight-month postoperative follow-up. No pulses were palpable in the ankles or 
feet. Both legs felt cool below knee level, but the skin and appendages appeared healthy. The right calf was tender with a positive Homan's sign. Neither the liver nor the spleen was palpable. Slight swelling, seemingly periarticular, of the volar aspeot of the left wrist and of the right ankle was noted.

INITIAL COURSE In the week following admission, the patient's temperature reached $38^{\circ} \mathrm{C}$ on two occasions and $37.8^{\circ} \mathrm{C}$ once. An evanescent petechial rash on the dorsum of the right foot was succeeded by a similar lesion over the right greater trochanter. Splinter haemorrhages were observed beneath the nails of the right fingers and, two weeks after entry, occlusion of the distal left ulnar artery was demonstrated using the Allen test. At this time pallor could be shown in both legs, with poor capillary filling and delayed dependent venous filling with redness, the changes being considerably worse in the right leg.

INVESTIGATIONS The haemoglobin on admission was $12.6 \mathrm{~g} / 100 \mathrm{ml}$; haematocrit $38 \%$; white cell count $8,200 / \mathrm{mm}^{3}$ (71 \% polymorphonuclear neutrophils, $9 \%$ easinophils, $15 \%$ lymphocytes, $5 \%$ monocytes) and the absolute eosinophil count three days later was $1,139 / \mathrm{mm}^{3}$; platelets $415,000 / \mathrm{mm}^{3}$; E.S.R. $56 \mathrm{~mm}$ in the first hour (Westergren); blood urea nitrogen 20 $\mathrm{mg} / 100 \mathrm{ml}$; electrolytes normal; proteins normal; antinuclear antibody negative; complement titre normal; no red cells in urine; repeated blood cultures for bacteria, rickettsia, and fungi were negative. The electrocardiogram was normal and cardiac radiology with fluoroscopy showed a prominent aorta (Fig. 1) and hyperdynamic heart.

BIOPSY In view of the suspected microembolic or vasculitic nature of the peripheral lesions, a skin and muscle biopsy was taken from the left foot. The epidermis and muscle underlying the dermis were normal. However, the lumen of many of the smaller vessels of the dermis, subcutaneous tissue, and tissue between muscle bundles was plugged and there was a perivascular infiltrate composed of neutrophils, lymphocytes, plasma cells, and occasional multinucleate histiocyte.3.

SUBSEQUENT COURSE On the 18th day in hospital the patient developed an acutely painful right foot, and

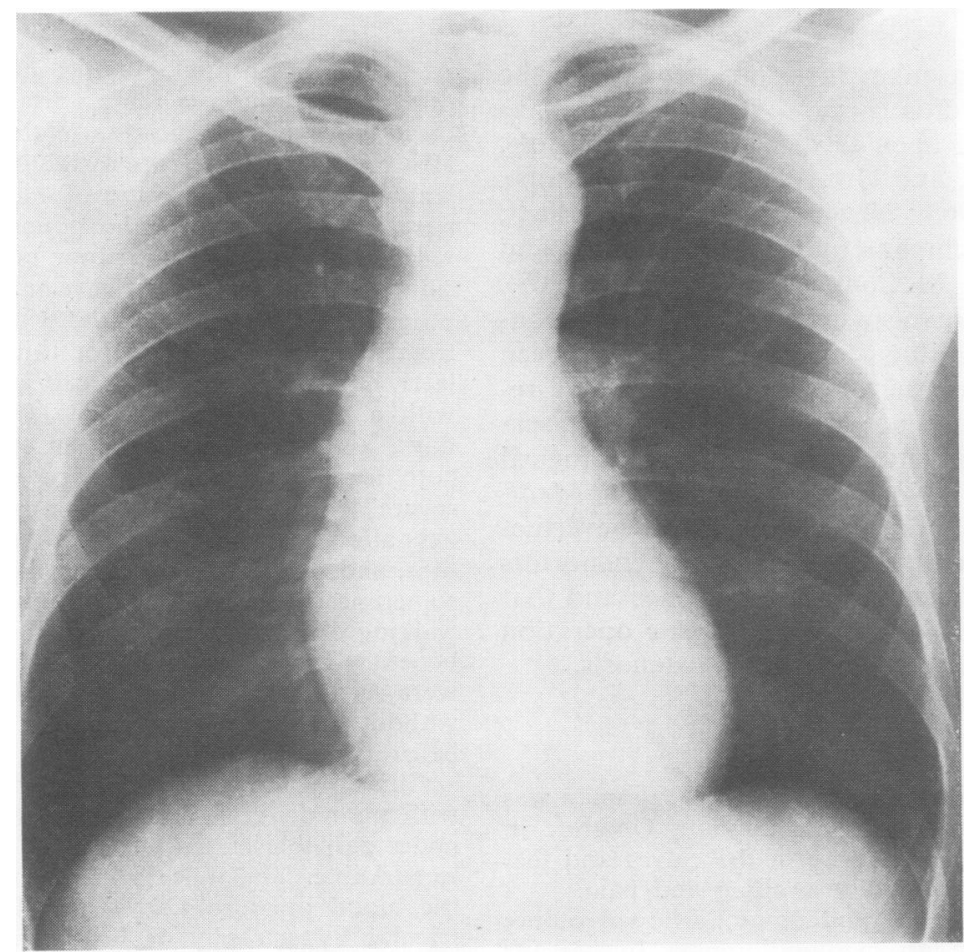

FIG. 1. Postero-anterior chest radiograph obtained on admission to hospital showing slight prominence of aortic arch but otherwise normal cardiac and mediastinal silhouette and clear lung fields. 


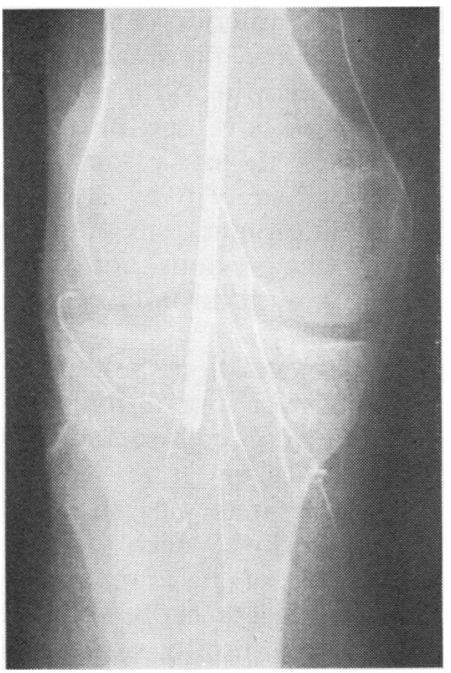

FIG. 2. Arteriogram showing occlusion of the distal part of the right popliteal artery.

there was a bounding right popliteal pulse with a cold and pale leg below mid-calf level. As before, the dorsalis pedis and posterior tibial pulses were impalpable. Femoral arteriography demonstrated abrupt occlusion of the right popliteal artery distally (Fig. 2). Embolectomy was performed by Fogarty catheter, with slight improvement of the extremity.

That night he vomited and next morning had severe headache with drowsiness, inattention, hypertonic paralysed left leg, left ankle clonus, and extensor left plantar response. A right carotid arteriogram showed displacement of vessels by an intracerebral mass in the posterior parieto-occipital region. A huge intracerebral clot and $25 \mathrm{ml}$ of liquid blood were evacuated through a trephine craniotomy, but no specific bleeding point was seen. Gradual neurological recovery followed with a return of left leg movement, but features of a right parietal lobe lesion persisted.

On day 20 histological sections of the embolus removed from the right leg were available and revealed numerous mycelia and spores of a septate fungus whose morphology was that of an aspergillus (Fig. 3). Intravenous amphotericin B therapy was begun; the blood urea nitrogen level was $26 \mathrm{mg} / 100 \mathrm{ml}$. Within three days the blood urea nitrogen had risen to $37 \mathrm{mg} / 100 \mathrm{ml}$ and the urine contained over 100 red cells $/ \mathrm{mm}^{3}$. The spleen remained impalpable throughout.

Headache again became troublesome on day 27 but little objective change was discernible until day 30 when drowsiness and left leg paralysis recurred. Right carotid arteriography again suggested a space-

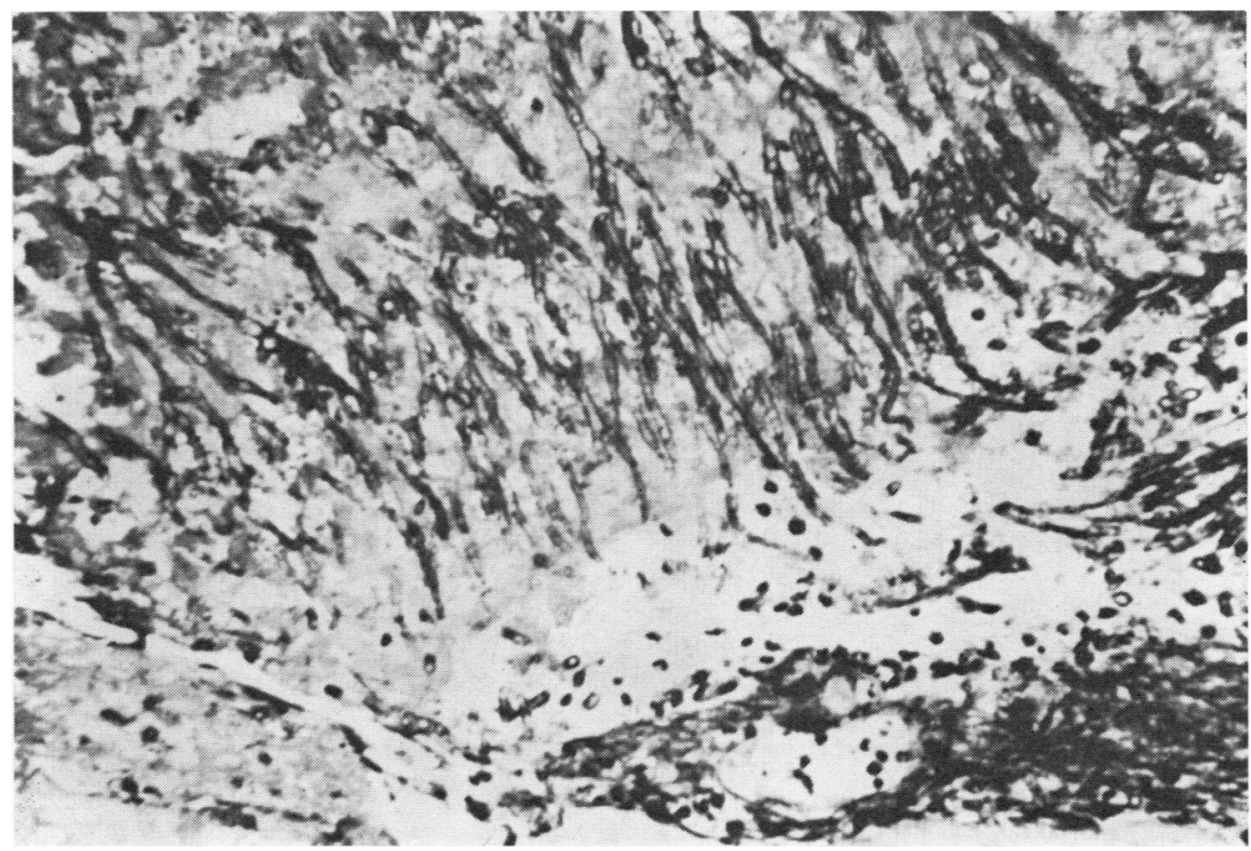

FIG. 3. Section of surgically recovered right popliteal artery embolus showing septate mycelium of A. flavus (P.A.S. stain $\times 250)$. 
occupying lesion in the region already evacuated and craniotomy revealed a granulomatous mass at the site of previous intracerebral clot with a few millilitres of pus and much oedema of adjacent brain. Postoperatively he remained drowsy and deteriorated progressively with failing respiratory drive and the development of decerebrate posturing culminating in death on the 35th day in hospital.

MYCOLOGICAL TECHNIQUE Mycological evaluation of a portion of the embolus was carried out and consisted of maceration and inoculation on to plates and tubes of Sabouraud dextrose agar medium, enriched with $0.5 \%$ yeast extract. These were incubated at $22^{\circ}$, $35^{\circ}$, and $40^{\circ} \mathrm{C}$, yielding heavy growths of aspergillus after three to four days. Further study of the morphology of its conidia and conidial heads showed it to be a member of the Aspergillus flavus group of fungi (Raper and Fennell, 1965).

NECROPSY The heart weighed $350 \mathrm{~g}$. The pericardium was thickened and fibrotic. The aortic valve was bicuspid and its orifice admitted one and a half fingertips (Fig. 4). Both cusps, but more particularly the anterior, were thickened and partially calcified. Close to one commissure, a reddish and superficially friable vegetation measuring $1 \mathrm{~cm}$ in diameter was found on the free border of the anterior cusp. The cusp was not perforated. Below the vegetation an endocardial pocket, $0.5 \mathrm{~cm}$ in width, was present. The aorta immediately above the posterior sinus of $\overrightarrow{\mathbb{D}}$ Valsalva was the site of a saccular dilatation $\triangle$ measuring approximately 6 by $3 \mathrm{~cm}$ and in the wall of this dilatation black silk sutures were seen $\vec{\circ}$ at the site of the previous aortotomy incision. (Fig. 5). Small mural thrombi were present in $\vec{\omega}$ scattered areas.

Sections of the vegetation showed fibrin but no $\vec{x}$ inflammatory cells or organisms. No fungi or 요 bacteria were grown on culture and the vegetation $\rightarrow$ was considered to be marantic. Multiple sections $\vec{\omega}$ through the aortic aneurysm showed numerous $O$ granulomata, many of which contained asper- $\stackrel{\circ}{\supset}$ gillus mycelia. Most of the granulomas were seen $\overrightarrow{\vec{c}}$ in the lamina media, especially about the sutured area, and a few superficially situated granulomas had eroded through the intima.

Other significant necropsy findings included . emboli and infarcts in the spleen and right kidney, early gangrene of both feet and lower legs, haemorrhagic infarcts of the brain in the distribution of the right middle cerebral and left posterior cerebral arteries, and bilateral acute broncho-

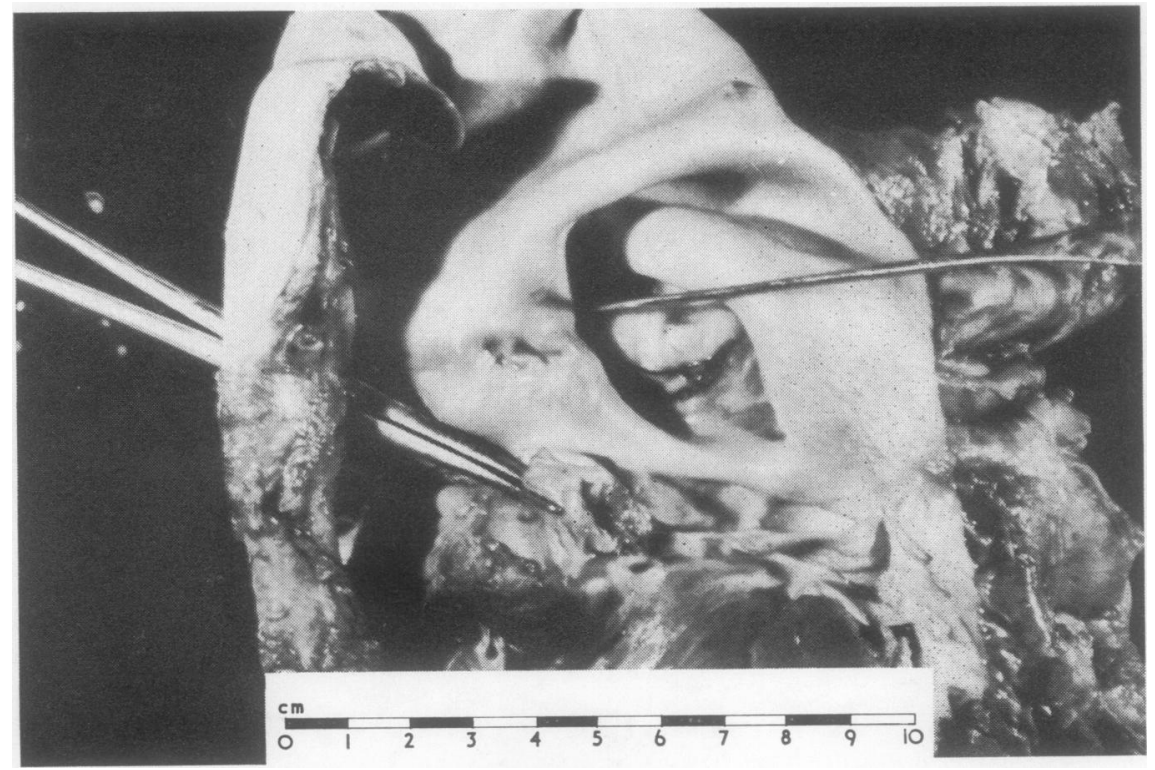

FIG. 4. Gross specimen showing bicuspid aortic valve and markedly dilated ascending aorta. Marantic vegetation attached to part of cusp held by forceps. Probe enters saccular dilatation of aorta in which crescentically placed black sutures are evident: multiple sections from this portion showed mycelia. 


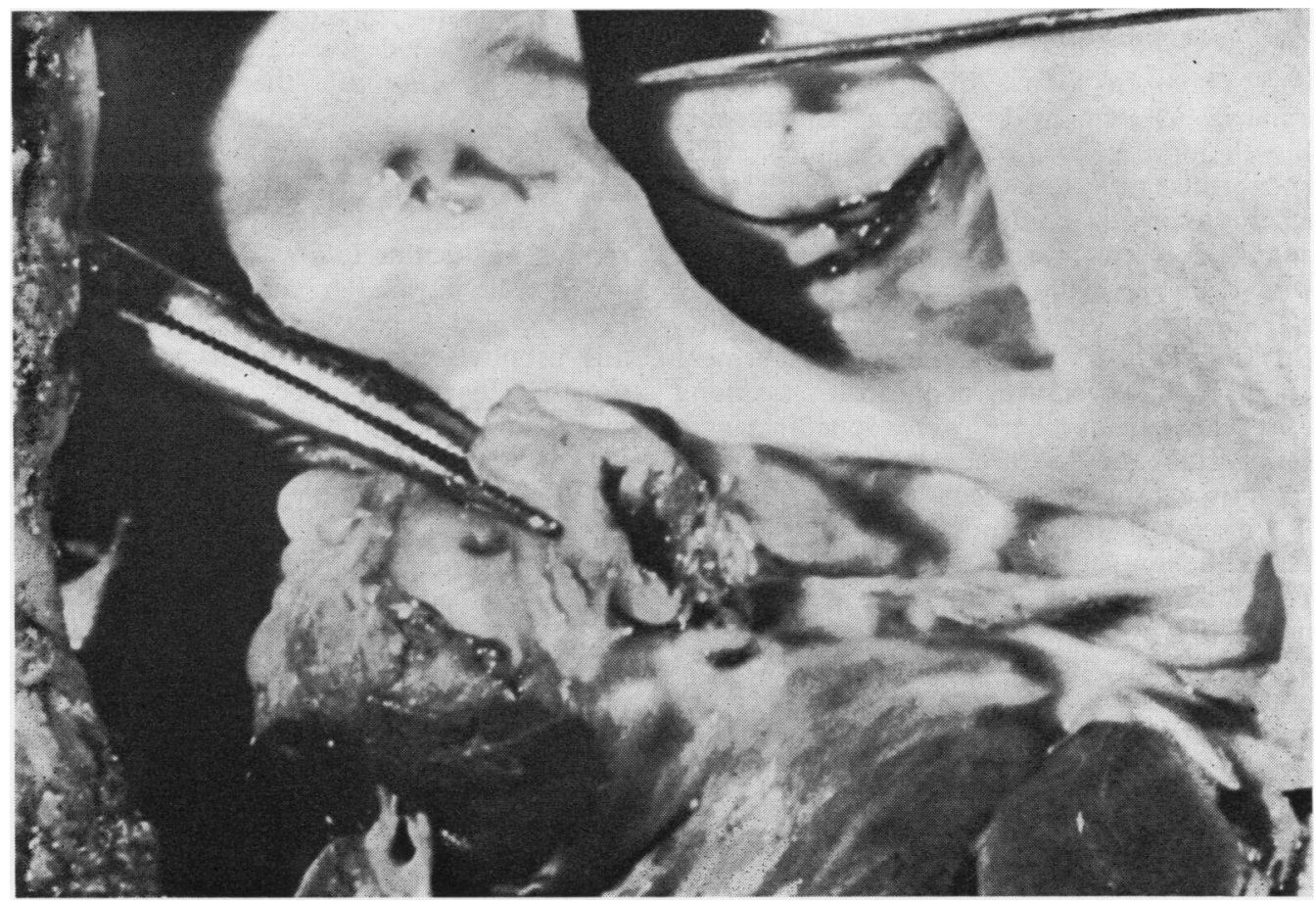

FIG. 5. Close-up of centre area of Fig. 4 showing marantic vegetation on aortic valve cusp and sutures at site of aortotomy.

pneumonia. The emboli in the kidney and spleen contained mycelia of the same type as those seen in the aorta and in the embolus surgically removed from the right popliteal artery before death. No emboli or fungi could be demonstrated in the brain.

\section{DISCUSSION}

This case of aspergillar endaortitis shares several important features of Hadorn's (1960) case in the Swiss literature including previous aortotomy, the occurrence of a large vessel embolus, and the recovery of embolic material enabling a tentative diagnosis to be made before death. Differentiation between endaortitis and endocarditis seems impossible on clinical grounds but the commoner occurrence of the latter condition must favour its choice. Non-surgical therapy would be identical for both groups and, on evidence available to date, the prognosis is uniformly hopeless. It therefore seems legitimate to review available reports of all forms of cardiovascular aspergillosis and to analyse current concepts relating to mycotic cardiovascular disease as a whole.
Several species of aspergillus have manifested cardiovascular pathogenicity but no correlation is apparent between species and type of lesion. The aspergillus in our case of endaortitis was of the species flavus and in Hadorn's (1960) case was $A$. fumigatus. In nine cases of vegetative endocarditis $\boldsymbol{A}$. fumigatus has been identified in four (Luke, Bolande, and Gross, 1963 ; Newman and Cordell, 1964 ; Caplan et al., 1968 ; News and Notes, British Medical Journal, 1970), A. flavus in two (Welsh and Buchness, 1955 ; Kirschstein and Sidransky, 1956), A. sydowi in one (Clinicopathological conference, 1969), and in two cases the species of aspergillus was not determined (Zimmerman, 1950). A. fumigatus focal granulomas and abscesses have been demonstrated in the myocardium and subendocardium of two patients (Cawley, 1947; Grekin, Cawley and Zheutlin, 1950), in one of whom the root of the aorta showed granulomatous involvement (Cawley, 1947). Purulent pericarditis together with abscess formation in dense fibrous tissue around the ascending aorta and in the myocardium has been reported with $A$. fumigatus (Fraumeni and Fear, 1962), and in one of two cases of the Budd- 
Chiari syndrome caused by aspergillar hepatic vein invasion fumigatus was the probable strain (Young, 1969). In a case of $\boldsymbol{A}$. niger systemic aspergillosis (Mahvi, Webb, Dixon, and Boone, 1968) with aortic 'saddle' embolus, no endocarditis or endaortitis was found at necropsy but an 'organizing embolus' containing numerous septate hyphae was present in a sinus of Valsalva. Of 98 patients with aspergillosis analysed in detail by Young, Bennett, Vogel, Carbone, and DeVita, (1970), seven had cardiovascular involvement but none had vegetative endocarditis. Among these seven patients there were four instances of pericarditis and in three instances extensive myocarditis was associated with large and small abscesses throughout the myocardium and smooth non-vegetative endocardial plaques: the causative aspergilli were not defined in terms of species. Hyphae of an unspecified aspergillus have been demonstrated in partially organized thrombus occluding the right coronary artery of a transplanted heart, with local myocardial necrosis plus fungal and polymorphous infiltration (Saunders and Bieber, 1968). Every case of cardiovascular aspergillosis in the reviewed literature has been fatal.

Aspergilli are widely distributed in nature and, in Canada, can be isolated from soil, silage, spoiling hay, and other sources. Members of the A. flavus group not only produce aflatoxin but are also important pathogens of the horse, pigeon, chicken, turkey, captive wild birds, and insects such as the honey bee. In man, the aspergillus can affect almost any part of the body although it is the respiratory system that is more frequently invaded, with saprophytic, allergic or septicaemic consequences (Hinson, Moon, and Plummer, 1952). In the past 15 years one of us (A. B.) has isolated several different species of aspergillus from more than 90 patients presenting a variety of clinical conditions, particularly notable being an increasing yield from patients on a renal transplantation programme.

Enhanced susceptibility to cardiovascular mycotic invasion attends protracted treatment with antibiotics, anti-inflammatory and immunosuppressive agents, illicit intravenous self-administration of drugs of addiction, and severely debilitating illness (Zimmerman, 1950 ; Merchant et al., 1958; Hudson, 1965; Lerner and Weinstein, 1966 ; Caplan et al., 1968 ; Conway, 1969 ; Ramsey, Gunnar, and Tobin, 1970) as well as cardiovascular surgery (Andriole et al., 1962; Jamshidi et al., 1963 ; Newman and Cordell, 1964 ; Climie and Rachmaninoff, 1965 ; Lerner and Weinstein, 1966 ; McConnell and Roberts, $\stackrel{\overline{5}}{\stackrel{5}{9}}$ 1967). Such evidence cautions against routine prophylactic antibiotic therapy after open-heart $\frac{\bar{\sigma}}{\bar{D}}$ surgery but impressive reductions in the incidence $\frac{\text { ? }}{\sigma}$ of endocarditis associated with prosthetic valve $\stackrel{\mathbb{\perp}}{\circ}$ replacement have followed the institution of routine antistaphylococcal prophylaxis with intra- $\vec{\circ}$ venous methicillin followed by oral oxacillin for:at least 10 days after valve implantation (Stein, $\vec{\omega}$ Harken, and Dexter, 1966). As experience with this prophylactic approach accumulates we may see that the price to be paid for reducing the ơ overall morbidity and mortality is an increase in + the incidence of complicating cardiovascular $\vec{\omega}$ mycoses. Consideration of the many risks in cardiac transplantation suggests that this is a par-음 ticular hazard and, indeed, the first such operation carried out in the United States was complicated by disseminated aspergillosis (Saunders and Bieber, 1968). A review of our patient's immediate $\theta$ postvalvotomy course revealed that he had. received ampicillin and cloxacillin, and he also응 received a three-day course of oral penicillin fors cellulitis of the hands two months later. It is a⿳亠二口犬 matter of conjecture as to whether direct tissue inoculation by airborne aspergilli occurred at $\frac{\mathbb{Q}}{\Omega}$ aortotomy, with postoperative mycotic prolifera $-\overrightarrow{\vec{c}}$ tion in the dilated aorta; whether intravenous catheters or cannulae provided a portal of entry? postoperatively; whether the cellulitis was associated with aspergillar invasion and a similar sequence of proliferation; or whether an entirelyo different pathogenetic process was involved. The symptoms of his illness and the physical signso clearly correlate with embolic phenomena and the sudden occlusion of a major vessel by a largeo vegetation embolus overwhelmingly favourse fungal rather than bacterial endocarditisg (Andriole et al., 1962 ; Jamshidi et al., 1963 ; McConnell and Roberts, 1967 ; Clinicopathologi-o․ㅡ. cal Conference, 1969, Williams, Viroslav, and Knight, 1970).

We emphasize the value of careful gross, histo logical, bacteriological, and mycological examina tion of surgically recovered embolic material. Suche evaluation of the popliteal artery embolus in this case and of aortic bifurcation 'saddle' emboli in two cases (Caplan et al., 1968 ; Mahvi et al., 1968) unequivocally established the diagnosis of cardio- $-\frac{0}{8}$ vascular aspergillosis and enabled antimycotiô. therapy to be instituted during life, albeit unsuc cessfully. Cases of candida endocarditis are or record which have responded to amphotericin (Louria and Dineen, 1960 ; Kroetz, Leonard, and Everett, 1962) but new possibilities have yet t@ 
be fully explored. In four cases of candida endocarditis reported by Kay, Bernstein, Tsuji, Redington, Milgram and Brem (1968) the technique of surgical removal of the gross nidus of infection has yielded three survivors, the two most recent having been subjected to valve excision, clearance of any visible intracardiac vegetation, prosthetic replacement of excised valve, and immediate postoperative amphotericin B therapy. Williams et al. (1970) have reviewed the recent impressive success of early valvular replacement as an adjunct to medical treatment in selected cases of bacterial endocarditis and they consider that the indications for valvular replacement early in the course of endocarditis are: (1) intractable or rapidly progressing heart failure despite specific medical therapy, (2) recurrent systemic or pulmonary emboli, and (3) unresponsive infection or overwhelming sepsis. The introduction of a potentially less toxic antimycotic therapeutic agent, 5-fluorocytosine, has been followed by reports of success in the treatment of candida septicaemia (Tassel and Madoff, 1968) and cryptococcal meningitis (Tassel and Madoff, 1968 ; Watkins et al., 1969) but its performance against the hitherto universally fatal entity of cardiovascular aspergillosis remains to be documented. Perhaps the final treatment of choice will prove to be a combination of surgical excision of the nidus of infection and the oral administration of 5-fluorocytosine.

The authors are grateful to Dr. Gerald A. Sears for permission to publish details of this case and acknowledge his encouragement and advice.

\section{REFERENCES}

Andriole, V. T., Kravetz, H. M., Roberts, W. C., and Utz, J. P. (1962). Candida endocarditis. Clinical and pathologic studies. Amer. J. Med., 32, 251.

Caplan, H. I., Frisch, E., Houghton, J. D., Climo, M. S., and Natsios, G. A. (1968). Aspergillus fumigatus endocarditis. Report of a case diagnosed during life. Ann. intern. Med., 68, 378.

Cawley, E. P. (1947). Aspergillosis and the aspergilli. Report of a unique case of the disease. Arch. intern. Med., 80, 423.

Climie, A. R. W., and Rachmaninoff, N. (1965). Fungal (Candida) endocarditis following open-heart surgery. J. thorac. cardiovasc. Surg., 50, 431.

Clinicopathological Conference (1969). A case of fungal endocarditis. Brit. med. J., 3, 765.

Conway, N. (1969). Endocarditis in heroin addicts. Brit. Heart J., 31, 543.

Fraumeni, J. F., Jr., and Fear, R. E. (1962). Purulent pericarditis in aspergillosis. Ann. intern. Med., 57, 823.

Grekin, R. H., Cawley, E. P., and Zheutlin, B. (1950). Generalized aspergillosis. Report of a case. Arch. Path., 49, 387.
Hadorn, W. (1960). Aortenruptur durch Aspergillusinfektion nach Operation einer Aortenstenose. Endaortitis polyposa mycotica. Schweiz. med. Wschr., 90, 929.

Hinson, K. F. W., Moon, A. J., and Plummer, N. S. (1952). Broncho-pulmonary aspergillosis. $A$ review and a report of eight new cases. Thorax, 7, 317.

Hudson, R. E. B. (1965). Cardiovascular Pathology, vol. 2, p. 1230. Arnold, London.

Jamshidi, A., Pope, R. H., and Friedman, N. H. (1963). Fungal endocarditis complicating cardiac surgery. Arch. intern. Med., 112, 370.

Kay, J. H., Bernstein, S., Tsuji, H. K., Redington, J. V., Milgram, M., and Brem, T. (1968). Surgical treatment of Candida endocarditis. J. Amer. med. Ass., 203, 621.

Kirschstein, R. L., and Sidransky, H. (1956). Mycotic endocarditis of the tricuspid valve due to Aspergillus flavus. Report of a case. Arch. Path., 62, 103.

Kroetz, F. W., Leonard, J. J., and Everett, C. R. (1962). Candida albicans endocarditis successfully treated with amphotericin B. New Engl. J. Med., 266, 592.

Lerner, P. I., and Weinstein, L. (1966). Infective endocarditis in the antibiotic era. New Engl. J. Med., 274, 199.

Louria, D. B., and Dineen, P. (1960). Amphotericin B in treatment of disseminated moniliasis. J. Amer. med. Ass., 174, 273.

Luke, J. L., Bolande, R. P., and Gross, S. (1963). Generalized aspergillosis and Aspergillus endocarditis in infancy. Report of a case. Pediatrics, 31, 115.

McConnell, E. M., and Roberts, C. (1967). Pathological findings in three cases of fungal endocarditis complicating open-heart surgery. J. clin. Path., 20, 555.

Mahvi, T. A., Webb, H. M., Dixon, C. D., and Boone, J. A. (1968). Systemic aspergillosis caused by Aspergillus niger after open-heart surgery. J. Amer. med. Ass., 203, 520.

Merchant, R. K., Louria, D. B., Geisler, P. H., Edgcomb, J. H., and Utz, J. P. (1958). Fungal endocarditis: Review of the literature and report of three cases. Ann. intern. Med., 48, 242.

Newman, W. H., and Cordell, A. R. (1964). Aspergillus endocarditis after open-heart surgery. Report of a case and review of literature. $J$. thorac. cardiovasc. Surg., 48, 652.

News and Notes (1970). Epidemiology: Mycoses. Brit. med. J., 2, 185.

Ramsey, R. G., Gunnar, R. M., and Tobin, J. R., Jr., (1970). Endocarditis in the drug addict. Amer. J. Cardiol., 25, 608.

Raper, K. B., and Fennell, D. I. (1965). The Genus Aspergillus, chap. 18. Williams and Wilkins, Baltimore.

Saunders, A. M., and Bieber, C. (1968). Pathologic findings in a case of cardiac transplantation. J. Amer. med. Ass., 206, 815.

Stein, P. D., Harken, D. E., and Dexter, L. (1966). The nature and prevention of prosthetic valve endocarditis. Amer. Heart. J., 71, 393.

Tassel, D., and Madoff, M. A. (1968). Treatment of Candida sepsis and Cryptococcus meningitis with 5-fluorocytosine. J. Amer. med. Ass., 206, 830.

Watkins, J. S., Campbell, M. J., Gardner-Medwin, D., Ingham, H. R., and Murray, I. G. (1969). Two cases of cryptococcal meningitis, one treated with 5-fluorocytosine. Brit. med. J., 3, 29.

Welsh, R. A., and Buchness, J. M. (1955). Aspergillus endocarditis, myocarditis and lung abscesses; report of a case. Amer. J. clin. Path., 25, 782. 
Williams, T. W. .Jr., Viroslav, J., and Knight, V. (1970). Management of bacterial endocarditis-1970. Amer. J. Cardiol., 26, 186.

Young, R. C. (1969). The Budd-Chiari syndrome caused by Aspergillus. Two patients with vascular invasion of the hepatic veins. Arch. intern. Med., 124, 754.
—, Bennett, J E., Vogel, C. L., Carbone, P. P., aspd DeVita, V. T. (1970). Aspergillosis. The spectrum of the disease in 98 patients. Medicine (Baltimore), 49, 14. Zimmerman, I . 1 (1950) .Candida and Aspergillus endocarditis, with comment: on the role of antibiotics हैn dissemination of fungus disease. Arch. Path., 50, 52. 